\title{
A study on pregnancy outcome following previous one spontaneous abortion
}

\author{
Archana Chandna ${ }^{1}$, Anoopa Sood ${ }^{1}$, Rita Mittal $^{1}$, Sandeep Soni $^{2}$ \\ ${ }^{1}$ Department of OBG, IGMC, Shimla, India \\ ${ }^{2}$ Department of psychiatry, PGIMS, Rohtak, India
}

Received: 16 September 2015

Revised: 26 October 2015

Accepted: 29 October 2015

\section{*Correspondence:}

Dr. Archana Chandna,

E-mail: archanachandna@gmail.com

Copyright: $\odot$ the author(s), publisher and licensee Medip Academy. This is an open-access article distributed under the terms of the Creative Commons Attribution Non-Commercial License, which permits unrestricted non-commercial use, distribution, and reproduction in any medium, provided the original work is properly cited.

\begin{abstract}
Background: Pregnancy plays a unique role in the transformation of women towards completeness. Pregnancy should be considered a unique normal physiological episode in a woman's life. However in some cases many twists and turns occur which alter the good outcome of pregnancy into a disaster. For those women who have had a previous unsuccessful outcome, pregnancy may bring a lot of inevitable negative emotions. The main objective of our study was to determine pregnancy outcome following previous one spontaneous abortion

Methods: A prospective study was done on 756 patients. There were 252 patients in the case group consisting of pregnant females with the history of previous one spontaneous abortion (group A). There were two control groups primigravida women (group B) \& second gravida with history of previous successful pregnancy outcome (group C) who delivered subsequent to our study group. All the antenatal, post natal complications and modes of delivery were noted and compared between the three groups.

Results: Pregnancy complications included: threatened miscarriage, premature rupture of membranes (PROM), preterm delivery, intra uterine growth restriction (IUGR), diabetes mellitus, abruption, placenta praevia, preeclampsia, eclampsia and postpartum hemorrhage (PPH). Statistical analysis was carried out using Statistical Package for Social Scientists (SPSS) version 20. Statistical analysis showed that all the complications except preeclampsia, eclampsia, placenta praevia and diabetes were more in the study group than both the control groups $(p<0.05)$. Risk of preeclampsia was more in primigravidae. Rate of caesarean section and instrumental delivery was also significantly increased in women with previous one spontaneous abortion.

Conclusions: Women with a history of previous one spontaneous abortion are at an increased risk of complications in the next pregnancy. So careful surveillance should be provided to such women and not to be restricted only to females with history of recurrent pregnancy loss
\end{abstract}

Keywords: Spontaneous abortion, Pregnancy complications

\section{INTRODUCTION}

Pregnancy plays a unique role in the transformation of women towards completeness. Pregnancy should be considered a unique normal physiological episode in a woman's life. However in some cases many twists and turns occur which alter the good outcome of pregnancy into a disaster. For those women who have had a previous unsuccessful outcome, pregnancy may bring a lot of inevitable negative emotions. ${ }^{1}$ Research into the reproductive consequences of miscarriage presents a number of challenges. The first involves the criteria for the diagnosis of the clinical entity itself. ${ }^{2}$ Studies looking at subsequent pregnancy outcomes are difficult to compare because the definition of "miscarriage" varies widely with gestational ages ranging from 13-28 weeks. ${ }^{3}$ 
National Centre for Health Statistics, Centres for Disease Control and prevention, and WHO define abortion as pregnancy termination prior to 20 weeks gestation or with a foetus born weighing less than $500 \mathrm{gm} .^{4}$ Recurrent miscarriages occur in only $1 \%$ of women. Despite their rarity, the effects of recurrent miscarriages on subsequent reproductive outcomes have dominated the literature. By contrast, a single miscarriage has not traditionally been perceived as a major clinical problem. ${ }^{2}$ Keeping all the above facts in mind we conducted a study in our department so as to determine whether a previous spontaneous miscarriage is associated with an increased rate of adverse pregnancy outcomes in the following pregnancy.

\section{METHODS}

This proposed prospective study was conducted in Department of Obstetrics And Gynaecology, Kamla Nehru State Hospital for Mother and Child, Indira Gandhi Medical College, Shimla, India from $1^{\text {st }}$ April 2012 to $31^{\text {st }}$ March 2013. It included:

A. Study group: All second gravida women with history of previous one spontaneous abortion who came to labour room after 20 weeks of gestation and delivered. Control groups were group B and C.

B. Primigravida women delivered subsequent to our study groups.

C. Second gravida women with history of previous successful pregnancy outcome and delivered subsequent to our study group.

There were 252 patients in study group and 252 in each of the control group.

\section{Exclusion criteria:}

A. Women with multiple pregnancy.

B. Women with history of previous induced abortion.

\section{Statistical analysis:}

Statistical analysis was carried out using Statistical Package for Social Scientists (SPSS) version 20. Continuous variables were compared using analysis of variance, while categorical variables by chi-square test and Fisher's exact (for value $<5$ in any cell). Crude odds ratios and their $95 \%$ confidence intervals were calculated. A $(p<0.05)$ was considered statistically significant.

\section{RESULTS}

Women in group B were younger compared to group A and $\mathrm{C}$ and the difference is statistically significant ( $\mathrm{p}$ value $=0.012$ for group $A$ and $B$ and $p$ value $=0.000$ for group A and C). Maximum number of females belonged to class IV (modified Kuppuswami scale) in all the three groups. There was no statistically significant difference between BMI of females in all the three groups. Pregnancy complications like threatened miscarriage, PROM, preterm labour, IUGR, abruption placentae, were significantly higher in group A compared to the other two groups. The risk of preeclampsia was more in primigravidas compared to other two groups and the difference was statistically significant. There was no statistically significant difference between the three groups with regard to Diabetes mellitus, placenta praevia, eclampsia and instrumental delivery. In group B significantly increased number of women underwent induction of labour, caesarean section and suffered PPH compared to other two groups.

\section{DISCUSSION}

According to the present study, previous spontaneous miscarriage adversely affects the outcome in next pregnancy. In terms of threatened miscarriage, PROM, and placental abruption present study is comparable to studies by Kashanian ${ }^{5}$, Bhattacharya ${ }^{2}$ and Weintraub et $\mathrm{al}^{4}$ who also have reported increased risk in the study group compared to both the control groups. The risk of placenta praevia was not increased after previous spontaneous abortion in the present study and also in studies by above three authors. Bhattacharya et $\mathrm{al}^{2}$ reported a statistically significant increased risk of diabetes mellitus in group A than group B and same as group $\mathrm{C}$, while in the present study there is no significant difference in the incidence of diabetes between three groups. Present study has reported a statistically significant increased risk of IUGR in the study group compared to other two groups which is comparable to the study by Bhattacharya et $\mathrm{al}^{2}$ and Weintraub et $\mathrm{al}^{4}$ but in contrast to the study by Kashanian ${ }^{5}$ at al who have reported increased risk in group $\mathrm{C}$ than group A. For preeclampsia there are conflicting results by various authors. A study by Strickland ${ }^{6}$ and Saftlas et $\mathrm{al}^{7}$ have shown results comparable to the present study i.e. risk is maximum in women becoming pregnant for the first time and least in those who had previous successful pregnancy outcome. There is some degree of protection offered by previous abortion but not as compared to previous full term pregnancy. Whereas a study by Weintraub et al have found opposite results. ${ }^{4}$ Women with a history of previous spontaneous abortion are at increased risk of developing preeclampsia than those who had previous successful pregnancy outcome. Present study has reported increased risk of induction of labour, pre term delivery, caesarean section and PPH in the study group compared to both the control groups. This is similar to study by Bhattacharya ${ }^{2}$ and Weintraub et $\mathrm{al}^{4}$. 
Table 1: Comparison of pregnancy complications between three groups.

\begin{tabular}{|c|c|c|c|c|c|c|c|c|c|c|c|}
\hline \multirow[t]{2}{*}{$\begin{array}{l}\text { S. } \\
\text { No }\end{array}$} & \multirow{2}{*}{$\begin{array}{l}\text { Pregnancy } \\
\text { complication }\end{array}$} & \multicolumn{2}{|c|}{$\begin{array}{l}\text { Group A } \\
(n=252)\end{array}$} & \multicolumn{2}{|c|}{$\begin{array}{l}\text { Group B } \\
(n=252)\end{array}$} & \multicolumn{2}{|c|}{$\begin{array}{l}\text { Group C } \\
(n=252)\end{array}$} & \multirow{2}{*}{$\begin{array}{l}\mathbf{P} \\
\text { value } \\
\text { A\&B }\end{array}$} & \multirow{2}{*}{$\begin{array}{l}\text { P value } \\
\text { A\&C }\end{array}$} & \multirow{2}{*}{$\begin{array}{l}\text { OR } \\
\text { A\&B }\end{array}$} & \multirow{2}{*}{$\begin{array}{l}\text { OR } \\
\text { A\&C }\end{array}$} \\
\hline & & No & $\%$ & No & $\%$ & No & $\%$ & & & & \\
\hline 1 & $\begin{array}{l}\text { Threatened } \\
\text { Miscarriage }\end{array}$ & 38 & 15.1 & 20 & 7.9 & 21 & 8.3 & 0.001 & 0.018 & 2.06 & 1.95 \\
\hline 2 & PROM & 48 & 19.1 & 18 & 7.2 & 14 & 5.6 & 0.000 & 0.000 & 3.08 & 4.0 \\
\hline 3 & Preterm delivery & 29 & 11.5 & 16 & 6.3 & 10 & 4.0 & 0.042 & 0.001 & 1.92 & 3.15 \\
\hline 4 & IUGR & 20 & 7.9 & 9 & 3.6 & 5 & 2.0 & 0.035 & 0.002 & 2.33 & 4.26 \\
\hline 5 & Diabetes & 8 & 3.2 & 2 & 0.8 & 7 & 2.8 & 0.110 & 1.000 & 4.10 & 1.15 \\
\hline 6 & Abruption & 9 & 3.6 & 2 & 0.8 & 1 & 0.4 & 0.033 & 0.025 & 4.63 & 9.30 \\
\hline 7 & Placenta previa & 4 & 1.6 & 0 & 0.0 & 4 & 1.6 & 0.123 & 1.000 & UD & 1.0 \\
\hline 8 & Preeclampsia & 8 & 3.2 & 18 & 7.1 & 4 & 1.6 & 0.044 & 0.380 & 0.43 & 2.03 \\
\hline 9 & Eclampsia & 2 & 0.8 & 3 & 1.1 & 2 & 0.8 & 1.000 & 1.000 & 0.66 & 1.0 \\
\hline 10 & Induction of labour & 89 & 35.5 & 66 & 26.1 & 40 & 15.9 & 0.026 & 0.000 & 1.54 & 2.89 \\
\hline 11 & Caesarean section & 44 & 17.5 & 24 & 9.5 & 25 & 9.9 & 0.009 & 0.013 & 2.01 & 1.92 \\
\hline 12 & Instrumental delivery & 10 & 4.0 & 8 & 3.2 & 3 & 1.2 & 0.631 & 0.091 & 1.26 & 3.43 \\
\hline 13 & PPH & 15 & 5.9 & 6 & 2.4 & 5 & 1.9 & 0.044 & 0.022 & 2.59 & 3.13 \\
\hline
\end{tabular}

\section{CONCLUSIONS}

Women with a history of previous one spontaneous abortion are at an increased risk of complications in the next pregnancy. So careful surveillance should be provided to such women and not to be restricted only to females with history of recurrent pregnancy loss.

Funding: No funding sources

Conflict of interest: None declared

Ethical approval: Approved by Institutional Ethical Committee

\section{REFERENCES}

1. Chalana H, Sachdeva JK. A study of psychiatric morbidity during second trimester of pregnancy subsequent to abortion in the previous pregnancy. Asian Journal of Psychiatry. 2012;5:215-19.

2. Bhattacharya S, Bhattacharya S. Women's Health. 2009;5:5-8.

3. Goldstein RRP, Croughan MS, Robertson PA. Neonatal outcomes in immediate versus delayed conceptions after spontaneous abortion. Am J Obstet Gynecol. 2002;186:1230-6.
4. Weintraub AY, Sergienko R, Harlev A, Holcberg G, Mazor M, Wiznitzer A, et al. Previous miscarriage and stillbirth as risk factors for other unfavourable outcomes in the next pregnancy. Am J Obstet Gynecol. 2011;205:286.e1-5.

5. Kashanian M, Akbarian AR, Baradaran H, Shabandoust SH. Pregnancy outcome following a previous spontaneous abortion (miscarriage). Gynecol Obstet Invest. 2006;61:167-70.

6. Strickland DM, Guzick DS, Cox K, Gant NF, Rosenfeld RC. The relationship between abortion in first pregnancy and development of Pregnancy induced hypertension in the subsequent pregnancy. Am J Obstet Gynecol. 1986;154:146-8.

7. Saftlas AF, Levine RJ, Klebanoff MA, Martz KL, Ewell MG, Morris CD, et al. Abortion, Changed Paternity, and Risk of Preeclampsia in Nulliparous Women. Am J Epidemiol. 2003;157:1108-14.

Cite this article as: Chandna A, Sood A, Mittal R, Soni S. A study on pregnancy outcome following previous one spontaneous abortion. Int J Reprod Contracept Obstet Gynecol 2015;6:1879-81. 